\title{
O PRINCÍPIO DA HUMANIDADE: DIGNIDADE DA PESSOA
}

\author{
HUMANA
}

Roberta Espinha Corrêa*

Resumo: O artigo traz ao debate a discussão teórica do conflito social, mais especificamente a sua relação com a violência contemporânea, época de muitas incertezas e desafios, diante de uma criminalidade estruturada e organizada de forma transnacional. Demonstraremos que a solução está no próprio Direito penal material e processual, que deve ser reforçado, para ser um direito efetivo de tutela do bem jurídico, amparado pelo Direito Constitucional. A prevenção e a repressão dessa criminalidade que visa destruir o Estado democrático de direito têm que se afirmar com base nos princípios constitucionais. O princípio tratado no artigo é o da humanidade, cuja proposta que se faz é a defesa da dignidade humana como bem jurídico.

Palavras-chave: Conflito social - Violência - Criminalidade estruturada Prevenção - Repressão - Direito penal material e processual - princípios constitucionais

Abstract: The article brings to the debate the theoretical discussion of the social conflict, specifically its relation with contemporary violence, period of many uncertainties and challenges, in face of a criminality structured and organized in a transnational way. We will demonstrate that the solution is in the material and procedural Criminal Law itself, that must be enforced, to be an effective guardian of the juristic asset, sustained by the Constitutional Law. The prevention and repression to this criminality that aims to destroy the Democratic State rule by the Law must assert themselves according to the constitutional principles. The principle brought up in the article is humanity, in which the proposal is the defense of human dignity as juristic asset.

Keywords: Social conflict - Violence - Structured Criminality - Prevention Repression - procedural and material Criminal Law - constitutional principles

\section{Sumário:}

Introdução; 1. Como solucionar: violência e medo nas cidades; 2. Princípio da humanidade da intervenção; 3. Princípio da humanidade e o direito penal da segurança; 4. Pela defesa da dignidade humana como bem jurídico; 5 . Considerações finais. Referências.

${ }^{*}$ Mestranda e doutoranda em Ciências Jurídicas na Universidade Autônoma de Lisboa. 


\section{I - INTRODUÇÃO}

Nos últimos anos, os conflitos têm crescido ao longo do território africano e de vários países do Oriente Médio. Historicamente falando, esses territórios sempre foram muito conflituosos, desde a época de colonização e descolonização, assim como na implantação de democracias e intervenções internacionais, além de viverem rebeliões e revoltas locais, mas sempre vivenciando vários ciclos de problemas. Com todos estes problemas e as guerras que estes locais vêm enfrentando ao longo do tempo, tornando, assim, precária a vida nestes lugares, ocorreram inúmeras migrações dessa população para regiões mais centrais e com melhores condições de vida. O destino natural destes refugiados na busca por uma nova vida é a Europa. Contudo, em função do grande número de refugiados que se deslocam para a Europa, o continente europeu está em plena crise humanitária e apesar dos esforços das Nações Unidas para buscar uma solução para este problema, ainda não há uma política migratória comum para tratar destes novos refugiados.

Ademais, o continente europeu ainda sofre com a existência de crimes como terrorismo, tráfico de armas, de pessoas, de órgãos, de drogas, corrupção, e existe entre eles a ideia de que todo refugiado é um potencial terrorista, criminoso, traficante... Sem dúvidas, existe uma grave crise humanitária que pode resultar em crises econômicas, políticas, sociais e muitas outras.

Diante deste quadro surgem os defensores do Direito Penal do Inimigo, como uma forma de tornar o inimigo inofensivo, através da eliminação preventiva do perigo, que é o próprio ser humano. Mas seria este o melhor caminho para combater a violência e o medo nas cidades, para solucionar este conflito entre refugiados e povos invadidos, assim como o combate aos crimes organizados? Entendemos que não, pois vemos a possibilidade do surgimento de uma nova perspectiva, do ponto de vista jurídico e social, para toda a comunidade europeia, em favor dos refugiados e imigrantes e contra a violência.

\section{II- COMO SOLUCIONAR: VIOLENCIA E MEDO NAS CIDADES}

"Se você quer a paz, cuide da justiça, advertia a sabedoria antiga - e, diferentemente do conhecimento, a sabedoria não envelhece." (BAUMANN, 
2007:11). "Uma vez investido sobre o mundo humano, o medo adquire um ímpeto e uma lógica de desenvolvimento próprios e precisa de poucos cuidados e praticamente nenhum investimento adicional para crescer e se espalhar irrefreavelmente". (BAUMANN, 2007:15)

Ao falarmos de violência e medo nas cidades, diante da existência de crimes como terrorismo, tráfico de armas, tráfico de drogas, tráfico de seres humanos, tráfico de órgãos, corrupção, lavagem de dinheiro e fraude econômico-financeira, dentre outros, entendemos que a solução dos problemas para se promover uma melhor e mais adequada prevenção e repressão da criminalidade estruturada e organizada transnacional, impõe-se que se reforce o Direito Penal material e processual, vigente e efetivo, como um Direito penal do bem jurídico e que se submetam a novos meios de investigação criminal, inclusive os próprios meios ocultos de investigação criminal, assim como os meios de investigação preventiva avançada - ou de campo avançado ou mesmo perseguição criminal de crimes - aos princípios regentes do Estado democrático de direito. Qualquer outra solução que não seja esta é negar o Direito Penal como direito assente em uma política criminal do ser humano. (VALENTE, 2014:11-12)

No breve estudo que pretendemos apresentar, analisaremos se o melhor caminho para se combater e prevenir estes crimes que são considerados os mais agressivos contra a humanidade seria utilizar o Direito Penal hoje para evitar questões futuras (a norma como manifestação constitutiva do Direito), como defendido por alguns, ao contrário da lógica do Direito Penal, que atua no presente, para aplicar sanção ao ocorrido no passado e não no futuro (a norma no tempo e o tempo na norma). Desta forma, como não somos defensores do Direito Penal do Inimigo preventivo, não aceitamos que se estabeleça como regra do Direito Penal prender alguém hoje porque teria chances de matar no futuro. O nosso estudo busca um caminho jurídico para o Direito Penal material e processual, amparado pelo Direito Constitucional. Assim, de forma oposta às posições que defendem o Direito Penal do inimigo, como a solução para o medo nas cidades e o combate a estes crimes organizados e transnacionais, entendemos que podemos avançar nos princípios da política criminal do ser humano, tais como: o princípio da legalidade ampla material (assente na igualdade), o princípio da culpabilidade que afasta a periculosidade e a 
segurança como princípios regentes da atuação penal, o princípio da humanidade da intervenção (penas e meios processuais) e o princípio do tratamento dos agentes dos crimes (prevenção especial positiva). (VALENTE, 2014:12-13)

Criminalizar comportamentos que representem pertencer a uma organização criminosa ou que representem um perigo social, como quer o Direito Penal do Inimigo, no qual o sujeito perigoso, rotulado como inimigo, caracteriza-se por ter abandonado o direito permanentemente, não seria o melhor caminho para o Direito Penal material e processual. O que se vê no Direito Penal do inimigo é uma guerra entre o Estado e o inimigo de forma a torná-lo inofensivo, ou seja, não se trata de um castigo por uma conduta reprovável de dano social, mas sim de uma eliminação preventiva da fonte de perigo que é o ser humano definido como perigoso e inimigo. Não podemos esquecer que em alguns Estados, através de uma ampliação da intervenção do Direito Penal, em relação aos meios de investigação criminal, restringindo direitos, liberdades e garantias - como ocorre com o Ato Patriótico dos Estados Unidos e a lei de segurança e combate ao terrorismo do Reino Unido (VALENTE, 2014:12-13) - é a total falta de amparo dessa intervenção penal nas Constituições vigentes nestes Estados. Entendemos que o Direito penal material e processual deverá estar sempre amparado pelos princípios constitucionais. E, dentre os princípios constitucionais que são fundamentais ao Direito Penal, temos convicção de que o principal, o primordial deles, é o princípio da dignidade da pessoa humana.

\section{III- PRINCIPIO DA HUMANIDADE DA INTERVENÇÃO}

“A negação de um cidadão como ser humano é reduzi-lo a indivíduo e a inimigo da ordem jurídica, é negar a axiologia inata ao Direito e negar o esforço e o sangue de nossos antepassados para que tivéssemos, hoje, um Direito que atua sobre seres humanos e não sobre coisas, que é aplicado por seres humanos e não por coisas, que foi criado, elaborado e aprovado por seres humanos e não por coisas." (VALENTE, 2014:12)

Com base no princípio humanista, afasta-se o direito penal material e processual do inimigo, que nada mais é do que uma "caça às bruxas, uma 
cruzada contra os malfeitores arqui-malvados, ou, mais recentemente, uma caça aos fantasmas" (ZAFFARONI, 1998:613-620). Necessário que defendamos a dignidade da pessoa humana como um bem jurídico.

A vigência de uma norma especial para inimigos é uma medida muito agressiva, que descreve um direito penal sem garantias, portanto, é inconstitucional! Se o Estado desconfia do cidadão, é possível ele se sentir seguro? Segundo Robert Castel, os países que se dizem avançados vivem em sociedades que estão entre as mais seguras que já existiram até hoje (CASTEL apud BAUMANN, 2009:13). Entretanto, de forma totalmente contrastante com essa evidência, os povos desenvolvidos sentem-se cada vez mais inseguros, ameaçados e amedrontados, inclinados ao pânico (BAUMANN, 2009:13).

Contudo, estamos falando da existência de novas classes perigosas, incapacitadas para a "reintegração e classificadas como não assimiláveis, porque não saberiam se tornar úteis, nem depois de uma reabilitação" (BAUMANN, 2009:22).

E assim, as cidades se transformaram em depósitos de problemas causados pela globalização. O que vemos é que os cidadãos e os políticos eleitos para representá-los estão diante de uma tarefa que não sabem como resolver: encontrar soluções locais para problemas e contradições globais (BAUMANN, 2009:32).

Um fenômeno presente na Europa, em especial, é a convivência com os estrangeiros, especificamente os refugiados, que trazem consigo o horror das guerras, da fome e escassez e representam o maior pesadelo para os povos invadidos, que é o medo de perder seus meios de sobrevivência e posição social. Os refugiados representam a fragilidade da condição humana, e ninguém quer lembrar dessas situações horríveis, todos os dias. Assim, esses imigrantes são os principais portadores das diferenças que provocam medo e insegurança, e por isso, os países considerados desenvolvidos necessitam demarcar suas fronteiras. Para estes imigrantes ou refugiados foi criada uma palavra cruel nos Estados Unidos, mas já está difundida na Europa: underclass ou subclasse. E ser underclass é estar fora do sistema de classes, é estar fora, excluído, não servir para nada. E no entendimento dos povos invadidos ou ameaçados de invasão, a sociedade seria melhor se o underclass desaparecesse por completo. E isso ocorre porque o que se prega de forma globalizada é o preconceito em relação 
ao underclass, considerados um lixo, parasitas e até mesmo terroristas em potencial, que cedo ou tarde irão matar os povos que invadiram ou tentam invadir (BAUMANN, 2009:79-83).

Mas o que fazer? Qual seria a solução?

A solução certamente está no próprio ser humano, pois se os seres humanos aceitam e apreciam outros seres humanos e procuram diálogo, certamente as diferenças culturais serão transponíveis. É totalmente possível pensar diferente e viver junto, pois viver com a diferença é uma arte, e se os seres humanos souberem respeitar essa diferença e salvaguardar a diversidade de um e aceitar a do outro, é totalmente possível essa convivência entre povos imigrantes ou refugiados e os habitantes locais.

Importante lembrarmos que os seres humanos são diferentes de animais e por isso podem ajudar um inválido a sobreviver, por exemplo. Pode-se dizer que historicamente a sociedade humana nasceu com a compaixão e com o cuidado com o outro, qualidades apenas humanas. Na visão de Baumann, a preocupação contemporânea está toda concentrada em como levar essa compaixão e essa solicitude para o nosso planeta. Gerações que nos precederam tiveram que enfrentar essa tarefa, mas no atual tempo, gostando ou não, é necessário prosseguir neste caminho e não há nada mais importante para se começar agora, imediatamente (BAUMANN, 2009:89-90).

O berlinense Georg Simmel, sociólogo cujo personagem mais importante de suas obras é a cidade moderna (Berlim, no caso para ele), entendia que os conflitos são laços fortes que nos unem e sem os quais a vida perde o sabor. $O$ lado trágico é vivermos na era do progresso (técnico e científico), na era da valorização da cultura objetiva, pois, em contrapartida, o ser humano não encontra o seu lugar, nem retorno, e assim o culto à violência é uma resposta às avessas. Portanto, a hostilidade acentua-se sob a forma de violência nas guerras, nas facções criminosas, no terrorismo, no tráfico de drogas, dentro do nosso cotidiano, até mesmo na "barbárie de matar por matar", ao lado do crescimento da cultura objetiva (CARVALHO, 2007:159). E diante dos problemas que afligem a sociedade moderna, dos conflitos, dos processos de alienação do indivíduo, da privação de liberdade, impostos pela cultura objetiva, e da intensificação da violência a cada dia, percebemos a dificuldade de encontrar 
um lugar onde conseguiremos que os limites sejam estabelecidos. (CARVALHO, 2007:161)

\section{IV- PRINCÍPIO DA HUMANIDADE E O DIREITO PENAL DA SEGURANÇA}

Tem-se falado muito nos últimos anos que o Direito Penal está evoluindo para um Direito da Prevenção de Perigos, tendo como alvos diretos o estabelecimento e a manutenção da segurança. Essa evolução realiza-se no momento em que as margens de ação dos cidadãos estão sendo cada vez mais restritas através das proibições jurídico-penais. Na Alemanha, especialmente nos anos 80 do século passado, ocorreram alterações no Código Penal da República Federal da Alemanha, tendo sido promovidas mudanças pelas quais a segurança prevalece sobre a liberdade (HASSEMER, 2006:76).

Seriam várias essas mudanças, como a agravação de proibições já existentes, mediante ameaças penais mais rigorosas, notadamente em algumas áreas, como economia, meio ambiente, processamento de dados e entorpecentes. Também passa o legislador a fazer uso cada vez mais da técnica de proteção fática do delito de perigo abstrato. Neste tipo de delito, ao contrário dos delitos de lesão clássicos, somente se exige como requisitos de punibilidade uma ação perigosa contra bens jurídicos e não mais a lesão de bens jurídicos. Outra tendência do legislador penal moderno é atender a bens jurídicos que são formulados de forma muito vaga e não mais aqueles voltados para interesses individuais de alguém, tornando o Direito Penal, assim, amplo e difuso. Exemplos neste caso seriam a manutenção da saúde pública e a proteção do mercado de capitais (HASSEMER, 2006:74).

Outra mudança significativa no processo penal moderno seria um aumento significativo dos métodos de investigação de forma muito sigilosa, devido à moderna tecnologia da comunicação, como serviços de escuta e observação. Inclusive através dessas tecnologias é possível estender essa investigação numa dimensão maior aos terceiros, com o emprego de investigadores ocultos, escuta telefônica, rastreamento de pistas, etc.

Enfim, no discurso político-penal atual houve uma mudança radical em relação às situações histórico-teóricas de outrora, nas quais os direitos 
fundamentais eram considerados direitos de defesa contra o Estado. O que se vê hoje é que não existe mais o Estado ameaçador de liberdade e o cidadão defensor de sua liberdade. Verifica-se que o Estado realizou uma mudança fundamental em relação ao seu papel perante os cidadãos, inclusive vista pelos próprios cidadãos. O Estado deixou de aparecer como aquele que ameaça os interesses de liberdade dos cidadãos. Ao contrário, o Estado cresceu e tornouse parceiro, aliado dos cidadãos, que são impulsionados pelo medo dos riscos e pelo temor dos crimes e por isso reivindicam que o Estado garanta a sua segurança.

Desta forma, a tensão que anteriormente existia entre a liberdade e a segurança dos cidadãos passou por uma mudança fundamental em favor da segurança, sendo que o Estado passa a corresponder a esses anseios da população, proporcionando-lhe segurança, ao invés de colocar em perigo a liberdade desta. Assim, o Estado deixa de ser uma ameaça de perigo para ser portador de esperança e aliado. (HASSEMER, 2006:77).

Nesta ideia é possível caminhar para um Direito Penal da Segurança baseado no Estado de Direito. A segurança através do Direito Penal é uma meta do Direito Penal e não de um Direito de Prevenção de Perigos, segundo Hassemer (HASSEMER, 2006:84). E Hassemer entende que todos os anseios por segurança que estiverem fora do Direito Penal, também com promessas de êxito, nada têm a fazer dentro do Direito Penal, porque o Direito Penal é e permanece ultima ratio. E isso significa que um Direito Penal da Segurança põe em primeiro plano a "peculiaridade, a personalidade e a dignidade da pessoa afetada, salvaguarda e protege sua autonomia pessoal e fortalece a perspectiva da liberdade". (HASSEMER, 2006:85).

Contudo, a necessidade de segurança, mais até do que a liberdade, conforme anteriormente dito, não pode se desvencilhar em momento algum do princípio da dignidade humana; há que estar sempre compatível a segurança com este princípio fundamental.

O artigo $1^{\circ}$ da Declaração Universal de Direitos Humanos, adotada pelas Nações Unidas em 10 de dezembro de 1948, diz o seguinte: “Todos os seres humanos nascem livres e iguais em dignidade e em direitos." A Constituição da República Federal da Alemanha, aprovada há 60 anos, inicia-se com um capítulo dedicado aos direitos fundamentais em seu artigo $1^{\circ}$, que assim começa: “A 
dignidade humana é inviolável." Portanto, a dignidade humana também desempenha, hoje, um papel proeminente no discurso internacional sobre os direitos humanos. Um fato interessante ocorrido na Alemanha em 2006 no que diz respeito à inviolabilidade da dignidade humana foi a rejeição pelo Tribunal Federal Constitucional da "Lei de Segurança da Aviação", aprovada pelo Parlamento federal, considerando-a inconstitucional. Essa lei, visando proteger as pessoas ameaçadas em terra pelo terrorismo (após o cenário de 11 de setembro nos Estados Unidos), autorizava as forças armadas a abater aviões de passageiros, que numa situação desse tipo tivessem se transformado em bombas. Contudo, na opinião do Tribunal, a morte de passageiros causada por órgãos estatais seria inconstitucional. Entendeu o Tribunal Constitucional alemão que a obrigação de respeitar a dignidade humana dos passageiros (conforme o $n^{\circ} .2$ do artigo $2^{\circ}$ da Constituição alemã) tem precedência sobre a obrigação do Estado de proteger a vida das potenciais vítimas de um atentado (HABERMAS, 2012:28-29). ${ }^{116}$

Corroborando a decisão do Tribunal Constitucional alemão, Habermas conclui que o "respeito pela dignidade humana de todas as pessoas interdita o Estado de dispor de um qualquer indivíduo como meio para um outro fim, mesmo que seja para salvar a vida de muitas outras pessoas" (HABERMAS, 2012:29).

Norberto Bobbio, ao falar da Declaração Universal dos Direitos Humanos adotada pela Assembleia Geral das Nações Unidas, entende que não há nenhum conflito na Declaração Universal, pois a proposição todos os seres humanos nascem livres e iguais é o mesmo que dizer que todos os seres humanos nascem igualmente livres ou mesmo que todos os seres humanos nascem iguais na liberdade, no duplo sentido da expressão, isto é, os seres humanos têm igual direito à liberdade ou os seres humanos têm direito a uma igual liberdade (BOBBIO, 2009:98). De acordo com o preâmbulo da Declaração Universal, o ideal comum que todos os povos e nações buscam é um fato histórico cuja importância necessita ser trazida à consciência de cada um de nós, e cada um

\footnotetext{
${ }^{116}$ Habermas cita à página 28 de sua obra "Um Ensaio sobre a Constituição da Europa", de 2012, que a decisão do Tribunal Constitucional alemão se baseou na obrigação de respeitar a dignidade humana, segundo o $n^{\circ} .2$ do artigo $2^{\circ}$ da Lei Fundamental. Contudo, é importante lembrar que este artigo diz que "Todos têm direito à vida e à integridade física".
} 
tem seu próprio pensamento e ação, então não temos como prever se a concretização desses ideais está próxima ou distante. Contudo, cada um de nós deve carregar sua própria pedra, por menor que seja, para a "construção do grande edifício" (BOBBIO, 2009:98).

E para finalizar este capítulo, ainda podemos citar Cesare Beccaria, que em 1764 escreveu: "O legislador deve ser um arquiteto hábil, que saiba ao mesmo tempo empregar todas as forças que podem contribuir para consolidar o edifício e enfraquecer todas as que possam arruiná-1o" (BECCARIA, 2016:72).

\section{V- PELA DEFESA DA DIGNIDADE HUMANA COMO BEM JURÍDICO}

Defendemos, assim, a dignidade da pessoa humana como bem jurídico.

No mundo moderno, as novas ameaças e os novos perigos que vão surgindo causam com eles o medo, a insegurança e a falta de confiança de que o Direito Penal do cidadão seja capaz de combater a criminalidade organizada, o terrorismo, o tráfico de armas, de seres, de órgãos e de drogas, ou mesmo crimes contra a autodeterminação sexual (com crianças, por exemplo) e tantos outros, destruindo, assim, a crença de que o Direito Penal comum está adequado para combater estes fenômenos, já que a criminalidade organizada transnacional é altamente especializada (econômico-financeira, bancária e cibernética), gerando, assim, uma maior lesividade social do que a criminalidade tradicional, também chamada de criminalidade de massa (VALENTE, 2016:63).

Todas essas ameaças e impunidades dos criminosos levam ao questionamento de qual é o Direito Penal que os cidadãos querem, se será necessário reinventar o Direito Penal ou se se aprofundará e desenvolverá um Direito Penal para a afirmação de um Direito Penal da liberdade e da humanidade, o Direito Penal do ser humano (VALENTE, 2016:64).

Pensamos que o único caminho para se buscar uma maior segurança não pode passar à distância da dignidade da pessoa humana. Qualquer mudança que se busque no Direito penal material e processual tem que estar inserida no princípio da humanidade. O princípio da dignidade da pessoa humana, consagrado no artigo $1^{\circ}$ da CRFB, também no artigo $1^{\circ}$ da CRP e também no art. $1^{\circ}$ da Constituição da Alemanha, refletem o princípio da humanidade como princípio regente de uma ordem jurídica que se inscreva como caminho da 
afirmação e valoração do ser humano. Impõe-se, assim, que a ciência jurídica crie os postulados científicos de uma ordem jurídica valorativa do ser humano, por ele ser o verdadeiro usufruidor e destinatário da construção normativa vinculante do ente público e do ente privado (VALENTE, 2013:56-57).

E com base neste princípio da humanidade, implica dizer que a consequência jurídica da infração tem de derivar da absoluta necessidade, caso contrário é tirânica e desumana e violadora da dignidade da pessoa humana.

\section{VI- CONCLUSÃO}

Concluímos, assim, que Constituições Republicanas que consagram a dignidade da pessoa humana como a base do Estado Democrático de Direito, tal qual ocorre em Portugal, deixam explícito que a pessoa humana está em lugar acima da organização política. Essa dignidade determina deveres de proteção em situações especiais propícias a graves atentados a essa dignidade, como é o caso dos refugiados, de detidos e tantos outros (CANOTILHO E MOREIRA, 2007:197-200).

Necessário afirmar que a dignidade da pessoa humana é um princípio que coenvolve todos os princípios relativos aos direitos e também aos deveres das pessoas e a posição do Estado perante elas (MIRANDA, 2016:280). E pode até haver uma ponderação da dignidade de uma pessoa com a dignidade da outra, mas não há ponderação entre a dignidade humana com qualquer outro princípio, fundamento, valor ou interesse (MIRANDA, 2016:280).

Não se pode olvidar que o ser humano que vive em um sistema de poder centralizado tenderá, de um modo geral, a maximizar um dos seus piores institutos humanos, como a ganância, a destrutibilidade, a acumulação de poder para si e a destruição de outros (CHOMSKY, 2014:85). Na realidade é um tipo de instinto que surge e atua em determinadas circunstâncias históricas, mas com certeza o que se busca é uma sociedade em que exista a probabilidade desse instinto ser reprimido e substituído por outros instintos mais saudáveis (CHOMSKY, 2014:85). Buscar a dignidade da pessoa humana com um bem jurídico é um caminho para alcançarmos essa sociedade.

Existe um grande desafio das sociedades consideradas desenvolvidas e que são as que propagam a democracia e a paz, que precisam fazer valer seu 
poder humano e político para buscar maneiras de resolver a situação do medo que prevalece nos seres humanos. Mas com certeza não será através da violência (pela qual os povos imigrantes e refugiados já passaram em suas terras de origem) que se resolverá essa situação. É necessário haver a sustentação do poder, mas também uma garantia de melhores perspectivas de vida, já que os países desenvolvidos são uma alternativa para a fuga da violência, para a esperança de muitos que há muito tempo não são tratados de forma humanizada em seus países de origem. Não podemos esquecer que toda sociedade é um produto de elementos desiguais (SIMMEL, 1986:52), mas todos têm em comum a dignidade da pessoa humana, todos têm o direito à vida e à sua integridade física.

Assim sendo, concluímos que qualquer solução pela qual se busque encontrar a paz e a segurança tem que passar pelo caminho da humanidade, pela dignidade da pessoa humana.

\section{VII- REFERÊNCIAS BIBLIOGRÁFICAS}

BAUMAN, Zygmunt- Tempos líquidos; tradução Carlos Alberto Medeiros. Rio de Janeiro: Zahar, 2007. ISBN 978-85-7110-993-3.

BAUMAN, Zygmunt- Confiança e Medo nas Cidades; tradução Eliana Aguiar. Rio de Janeiro: Zahar, 2009. ISBN 978-85-378-0122-2.

BECCARIA, Cesare - Dos Delitos e das Penas. $2^{\mathrm{a}}$ ed. São Paulo: Edipro, 2016. ISBN 97885-7283-925-9.

BOBBIO, Norberto- o Terceiro Ausente. Barueri: Manole, 2009. ISBN 978-85-98416-66-3.

CANOTILHO, J.J. Gomes; MOREIRA, Vital - Constituição da República Portuguesa Anotada, volume 1. São Paulo: Revista dos Tribunais, 2007. ISBN 978-85-203-3044-9.

CARVALHO, Giane Alves- Conflito, violência e tragédia da cultura moderna: reflexões à luz de Georg Simmel. Revista Brasileira de Segurança Pública. Ano1. ed. 2, 2007.

FOUCAULT, Michel; CHOMSKY, Noam- Natureza Humana Justiça vs. Poder. São Paulo: WMF Martins Fontes. 2014. ISBN 978-85-7827-793-2.

HABERMAS. Jurgen- Um Ensaio sobre a Constituição da Europa. Lisboa: Edições 70. 2012. ISBN 978-972-44-1700-4.

HASSEMER, Winfried- Sobre a Arquitetura de um Direito Penal da Segurança, In: Direito Público [Em linha] nº14, 2006. Doutrina Estrangeira. Pág. 76. [Consult. 1 Jul. 2017]. Disponível em: 
http:www.portaldeperiodicos.idp.edu.be/direitopublico/search/authors/view?firstName=Winfri ed\&middleName $=\&$ lastName $=$ Hassemer $\&$ affiliation $=\&$ country $=$

JAKOBS, Gunther; MELIÁ, Manuel Câncio; org. e trad. CALLEGARI, André Luís, GIACOMOLLI, Nereu José- Direito Penal do Inimigo Noções e Críticas. 6. ed. Porto Alegre: Livraria do Advogado, 2015. ISBN 978-85-7348-792-3.

MACHADO, Jónatas - Direito Internacional. $4^{\mathrm{a}}$ ed. Coimbra: Coimbra, 2013. ISBN 978972-32-2181-7.

MIRANDA, Jorge - Curso de Direito Constitucional Estado e Constitucionalismo. Constituição. Direitos Fundamentais. Volume 1. Lisboa: Universidade Católica, 2016. ISBN 9789725405123.

SIMMEL, Georg- Sociologia: estúdios sobre las formas de socialización. Madrid: Alianza, 1986a. ISBN 9788420624792.

VALENTE, Manuel Monteiro Guedes- Direito Penal do Inimigo e o Terrorismo. 2.ed. Coimbra: Almedina, 2016. ISBN 978-858-49-3124-8.

VALENTE, Manoel Monteiro Guedes- A Ciência Jurídica como Caminho de Afirmação e Valorização do Ser Humano. In: Revista da Procuradoria-Geral do Estado de São Paulo. Jan/Dez 2013, vol. 4- Número 1, pp.49-62.

VALENTE, Manuel Monteiro Guedes- Os desafios do processo penal do estado democrático de direito: A sociedade internético-personocêntrica. In: III Seminário do IBADPP- Processo Penal e Democracia. [Em linha]. Salvador:2014 [Consult.10. Jun. 2017]. Disponível em: http://www.ibadpp.com.br/category/artigosinternacionais.

ZAFFARONI, Raul E.- "La Creciente legislación penal y los discursos de emergência". En: Varios autores. Teorias Actuales en el Derecho Penal. Buenos Aires: Ad-Hoc, 1998. 